\title{
Determination of Krebs Cycle Metabolic Carbon Exchange In Vivo and Its Use to Estimate the Individual Contributions of Gluconeogenesis and Glycogenolysis to Overall Glucose Output in Man
}

\author{
A. Consoli, ${ }^{*}$ F. Kennedy, ${ }^{\ddagger}$ J. Miles, ${ }^{\ddagger}$ and J. Gerich* \\ ${ }^{*}$ Diabetes Section, Division of Endocrinology, Departments of Medicine and Physiology, University of Pittsburgh, School of Medicine, \\ Pittsburgh, Pennsylvania 15261; and ${ }^{\ddagger}$ Endocrine Research Unit, Mayo Clinic, Rochester, Minnesota 55901
}

\begin{abstract}
Current isotopic approaches underestimate gluconeogenesis in vivo because of Krebs cycle carbon exchange and the inability to measure intramitochondrial precursor specific activity. We therefore applied a new isotopic approach that theoretically overcomes these limitations and permits quantification of Krebs cycle carbon exchange and the individual contributions of gluconeogenesis and glycogenolysis to overall glucose output. $\left[6-{ }^{3} \mathrm{H}\right]$ Glucose was infused to measure overall glucose output; $\left[2-{ }^{14} \mathrm{C}\right]$ acetate was infused to trace phosphoenolpyruvate gluconeogenesis and to calculate Krebs cycle carbon exchange as proposed by Katz. Plasma $\left[{ }^{14} \mathrm{C} / 3-\mathrm{OH}\right.$-butyrate specific activity was used to estimate intramitochondrial acetyl coenzyme A (CoA) specific activity, and finally the ratio between plasma glucose ${ }^{14} \mathrm{C}$-specific activity and the calculated intracellular phosphoenolpyruvate ${ }^{14} \mathrm{C}$-specific activity was used to determine the relative contributions of gluconeogenesis and glycogenolysis to overall glucose output. Using this approach, acetyl CoA was found to enter the Krebs cycle at twice (postabsorptive subjects) and three times ( $21 / 2-d$ fasted subjects) the rate of pyruvate, respectively. Gluconeogenesis in postabsorptive subjects (3.36 $\pm 0.20 \mu \mathrm{mol} / \mathrm{kg}$ per $\mathrm{min})$ accounted for $28 \pm 2 \%$ of overall glucose output and increased twofold in subjects fasted for $21 / 2-d(P<0.01)$, accounting for $>97 \%$ of overall glucose output. Glycogenolysis in postabsorptive subjects averaged $8.96 \pm 0.40 \mu \mathrm{mol} / \mathrm{kg}$ per $\mathrm{min}$ and decreased to $0.34 \pm 0.08$ $\mu \mathrm{mol} / \mathrm{kg}$ per min $(P<0.01)$ after a $21 / 2-d$ fast. Since these results agree well with previously reported values for gluconeogenesis and glycogenolysis based on determinations of splanchnic substrate balance and glycogen content of serial liver biopsies, we conclude that the isotopic approach applied herein provides an accurate, noninvasive measurement of gluconeogenesis and glycogenolysis in vivo.
\end{abstract}

\section{Introduction}

It has long been recognized that metabolic exchange of carbons in the Krebs cycle is a major factor limiting the isotopic quantification of gluconeogenesis in vivo $(1,2)$. The problem

Dr. Consoli is on leave from the Department of Medicine, University of Chieti, Chieti, Italy. Address correspondence and reprint requests to Dr. Gerich, Clinical Research Center, 3488 Presbyterian-University Hospital, 230 Lothrop St., Pittsburgh, PA 15261.

Received for publication 9 March 1987 and in revised form 27 May 1987.

J. Clin. Invest.

(c) The American Society for Clinical Investigation, Inc. 0021-9738/87/11/1303/08 $\$ 2.00$

Volume 80, November 1987, 1303-1310 arises because oxaloacetate is an intermediate common to both gluconeogenic and oxidative pathways in mitochondria. As a consequence, some of the labeled carbons of infused glucose precursors, such as $\left[{ }^{13} \mathrm{C}\right]-$ or $\left[{ }^{14} \mathrm{C}\right]$ lactate and alanine, are lost as $\mathrm{CO}_{2}$ and are replaced by unlabeled carbons originating from acetyl coenzyme $\mathrm{A}(\mathrm{CoA})^{1}(2)$. This dilution of the specific activity (sp act) of gluconeogenic intermediates reduces the sp act of glucose formed from these intermediates and results in an underestimation of glucose derived from the labeled precursors (i.e., gluconeogenesis).

This limitation could be overcome if it were possible to quantitate carbon exchange in the Krebs cycle. Indeed, more than 30 years ago, Strisower (3) developed a model based on in vitro experiments, the power series equations of which could be used to calculate Krebs cycle carbon exchange in vivo. Recently, Hetenyi and colleagues have used this model to obtain a correction factor for Krebs cycle carbon exchange in the rat and $\operatorname{dog}(4,5)$. Katz and colleagues (6-8) have described the same mitochondrial model in terms of inflow-outflow equations.

In the approach of Katz (8), one estimates the relative input of pyruvate (gluconeogenic pathway) and acetyl CoA (oxidative pathway) in the Krebs cycle by determining the distribution of labeled carbons within the glucose molecule during infusion of a labeled precursor, since this distribution is a function of the relative molar influx of pyruvate and acetyl CoA into the oxaloacetate pool $(1,3)$. According to this model (8), if one infuses $\left[2-{ }^{14} \mathrm{C}\right]$ acetate, the resultant ratio of the specific activities of carbons 1 and 3 in glucose will equal $2+2 Y$, where $\mathrm{Y}$ is the ratio of moles of pyruvate and $\mathrm{CO}_{2}$ entering the oxaloacetate pool relative to those of acetyl CoA entering the oxaloacetate pool. Thus, from the relative sp act of individual plasma glucose carbons, one should be able to estimate Krebs cycle carbon exchange in vivo.

Moreover, one should also be able to use this approach to estimate the relative contributions of glycogenolysis and gluconeogenesis to overall glucose output in vivo. From the value obtained for $\mathrm{Y}$ and the intramitochondrial specific activity of a labeled gluconeogenic precursor, it is possible, using the equations of Katz (8), to calculate the sp act of intramitocondrial phosphoenolpyruvate corrected for metabolic exchange. Since glucose formed directly from phosphoenolpyruvate has the same specific activity as phosphoenolpyruvate, the extent to which plasma glucose sp act is less than that of phosphoenolpyruvate will reflect the amount of unlabeled glucose entering

1. Abbreviations used in this paper: CoA, coenzyme A; mrem, milliroentgen; $P$, ratio of the intracellular phosphoenolpyruvate specific activity to the intramitochondrial acetyl CoA carbon specific activity; sp act, specific activity. 
plasma from glycogenolysis and from gluconeogenesis via pathways other than phosphoenolpyruvate.

The only major substrate that theoretically could be converted to glucose without entering the phosphoenolpyruvate pathway is glycerol. Since $<3 \%$ of plasma glucose is derived from glycerol in postabsorptive man $(9,10)$ (and some glycerol may actually traverse the phosphoenolpyruvate pathway on its way to glucose [11]), the ratio of the measured plasma glucose sp act relative to that of phosphoenolpyruvate should reflect the proportion of glucose output due to virtually all of gluconeogenesis, with the remainder being attributable to glycogenolysis.

The present experiments were, therefore, undertaken to determine Krebs cycle carbon exchange in man and to use this determination to estimate the relative contributions of gluconeogenesis and glycogenolysis to overall glucose output. Studies were performed in normal human volunteers fasted overnight, as well as for $66 \mathrm{~h}$, to test the validity of the approach of Katz (8), since after a 60-h fast essentially all of glucose output should be due to gluconeogenesis (12). For this purpose, we infused $\left[6-{ }^{3} \mathrm{H}\right]$ glucose to determine overall glucose output and $\left[2-{ }^{14} \mathrm{C}\right]$ acetate to serve both as a tracer for the phosphoenolpyruvate gluconeogenic pathway and as a means to determine Krebs cycle carbon exchange using the equations of Katz (8); plasma [14C]3-OH-butyrate sp act was used as an approximation of intramitochondrial $\left[{ }^{14} \mathrm{C}\right]$ acetyl $\mathrm{CoA}$ sp act (8), and the ratio of the $\left[{ }^{14} \mathrm{C}\right]-\mathrm{sp}$ act of plasma glucose and intracellular phosphoenolpyruvate was used to calculate the relative contributions of glyconeogenesis and glycogenolysis to overall glucose output.

\section{Methods}

Subjects. Informed written consent was obtained from nine male and five female healthy volunteers whose characteristics are given in Table I. All were between 90 and $120 \%$ of their ideal body weight (Metropoli$\tan$ Life Insurance Co. Tables, 1985), and none had a family history of diabetes mellitus. Each subject consumed a weight-maintenance diet containing at least $200 \mathrm{~g}$ carbohydrate and abstained from alcohol for 3 d before experiments.

Table I. Characteristics of Subjects Studied

\begin{tabular}{cllll}
\hline Subject & Sex & Age & Height & Weight \\
\hline & & $y r$ & $c m$ & $k g$ \\
2 & F & 47 & 164 & 71.4 \\
3 & M & 22 & 173 & 67.5 \\
4 & M & 20 & 192 & 98.5 \\
5 & M & 24 & 168 & 63.1 \\
6 & F & 37 & 156 & 59.3 \\
7 & F & 24 & 157 & 67.0 \\
8 & F & 34 & 165 & 64.7 \\
9 & M & 40 & 180 & 90.6 \\
10 & M & 61 & 168 & 76.0 \\
11 & M & 46 & 180 & 70.4 \\
12 & M & 47 & 172 & 69.5 \\
13 & F & 55 & 159 & 76.0 \\
14 & M & 31 & 175 & 78.0 \\
Mean & M & 42 & 169 & 67.5 \\
\pm SEM & & 38 & 170 & 72.8 \\
& & 3 & 3 & 2.8 \\
\hline
\end{tabular}

F, Female; M, male.
Protocol. All subjects were admitted to our Clinical Research Center between 5 and 7 p.m., given a standard meal (10 kcal $/ \mathrm{kg} ; 50 \%$ carbohydrate, $35 \%$ fat, and $15 \%$ protein), and studied the next morning after a 12-14-h fast. 10 of the 14 subjects were also studied after a 66-h fast, which was separated from the overnight fast experiments by at least 2 wks. When subjects were studied after an overnight fast, a continuous infusion of $\left[2-{ }^{14} \mathrm{C}\right]$ acetate $(1 \mu \mathrm{Ci} / \mathrm{min}$, Research Products International, Mount Prospect, IL) was started at 5 a.m. and a primed-continuous infusion of $\left[6{ }^{3} \mathrm{H}\right] \mathrm{glucose}(20 \mu \mathrm{Ci}, 0.2 \mu \mathrm{Ci} / \mathrm{min}$, New England Nuclear, Boston, MA) was started at 7 a.m. 4 and 2 h were allowed for isotopic equilibration of the $\left[2-{ }^{14} \mathrm{C}\right]$ acetate and [6${ }^{3} \mathrm{H}$ ]glucose infusions, respectively. In preliminary experiments, it was determined that these periods were sufficient to achieve steady state plasma $\left[{ }^{3} \mathrm{H}\right]$ glucose, $\left[{ }^{14} \mathrm{C}\right]$ glucose, and $\left[{ }^{14} \mathrm{C}\right] 3-\mathrm{OH}$-butyrate specific activities. Two plasma samples were then drawn at 20-min intervals for determination of plasma $\left[{ }^{14} \mathrm{C}\right]$ - and $\left[{ }^{3} \mathrm{H}\right]$ glucose sp act, plasma $\left[{ }^{14} \mathrm{C}\right] 3$ $\mathrm{OH}$-butyrate sp act, and the ${ }^{14} \mathrm{C}$-sp act of individual plasma glucose carbons. When subjects were studied after a 66-h fast, they were admitted to the Clinical Research Center between 4 and 5 p.m. of day 1, were given a standard meal $(10 \mathrm{kcal} / \mathrm{kg} / 50 \%$ carbohydrate, $35 \%$ fat, and $15 \%$ protein), and subsequently received only water ad lib. over the next $66 \mathrm{~h}$, after which they were studied in a manner identical to that of the overnight fast experiments.

\section{Analytical procedures}

$\left[{ }^{3} \mathrm{H}\right]-$ and $\left[{ }^{14} \mathrm{C}\right]$ glucose sp act and glucose labeling pattern. Glucose isolated from $4 \mathrm{ml}$ of plasma using ion exchange chromatography (13) was enzymatically cleaved to lactate (14), which was isolated by ion exchange chromatography (13). The lactate eluate was dried (Speed Vac rotor concentrator, Savant Instruments, Inc., Hicksville, NJ) and resuspended in $0.20 \mathrm{ml}$ of water. A $0.02-\mathrm{ml}$ aliquot was dried again and saved for subsequent lactate sp act determination by a high performance liquid chromatography (HPLC) method described below. The remaining lactate was oxidized to acetate using $\mathrm{KMnO} 4$ (15). The resultant acetate (carbons 1 and 2, and carbons 5 and 6 of the original glucose molecule) was extracted into chloroform (56\%), heptane $(42 \%)$, and methanol $(2 \%)(10: 1 \mathrm{vol})$. The extraction procedure was repeated three times to increase recovery $(\sim 55 \%)$. The combined organic phases were back extracted into $6 \mathrm{ml}$ of $0.01 \mathrm{~N} \mathrm{NaOH}$. The extract was dried, resuspended together with the previously isolated lactate in $0.14 \mathrm{ml}$ of $0.05 \mathrm{~N} \mathrm{H} 3 \mathrm{PO} 4$, and transferred to a $0.25-\mathrm{ml}$ cuvette to which $0.02 \mathrm{ml}$ of a $50 \%$ suspension of AG-50 W-XB resin, hydrogen form (Bio-Rad Laboratories, Richmond, CA) in $\mathrm{H} 2 \mathrm{O}$ was added. The cuvette was spun in a microfuge $B$ (Beckman Instruments Inc., Palo Alto, CA) and was loaded onto the deck of an automatic HPLC injector (WISP 110B; Waters Assoc., Milford, MA); $0.1 \mathrm{ml}$ of the sample was injected onto an Aminex $300 \times 7.8-\mathrm{mm}$ organic acid analysis column protected by a $40 \times 4.6-\mathrm{mm}$ Aminex guard column (Bio-Rad Laboratories) and eluted with $0.05 \mathrm{M} \mathrm{H} 3 \mathrm{PO} 4$ at $0.6 \mathrm{ml} / \mathrm{min}$ by a $114 \mathrm{M}$ LC pump (Beckman Instruments Inc.). The column effluent was passed through a 441 ultraviolet (UV) $(214 \mathrm{~mm})$ detector (Waters Assoc.) to a Retriever III fraction collector (ISCO, Lincoln, $\mathrm{NE}$ ); data were collected and analyzed by a Spectra-Physic $\mathbf{4 2 7 0}$ integrator, which was programmed to control the fraction collector.

Under these conditions, lactate and acetate were clearly separated with respective retention times of 13.7 and $16.5 \mathrm{~min}$. Lactate and acetate peaks were collected in separate scintillation vials; $15 \mathrm{ml}$ of scintillation fluid (Research Products International) were added and the ${ }^{14} \mathrm{C}$-radioactivity was counted in a liquid scintillation spectrometer. Standard curves of lactate and acetate, generated by injecting known quantities and plotting peak heights versus content (in nanomoles), were run in duplicates before each set of samples to allow the quantitation of the substrates in the samples from peak height; specific activity was determined by dividing the disintegrations per minute in the collected sample by the calculated content. From sp act of the lactate and acetate fractions of the original glucose molecule, the ratio of the $\mathrm{sp}$ act of the external carbons $(1,2,5$, and 6$)$ to the internal carbons (3 
and 4) was obtained according to the formula: $R=$ acetate sp act $/ 2$ (lactate sp act - acetate sp act).

Acceptable precision of this technique is indicated by the fact that degradation of $\left[\mathrm{U}-{ }^{14} \mathrm{C}\right] \mathrm{glucose}$ standards (Research Products International) by this technique resulted in a value for $R$ of $1.04 \pm 0.02$ with a coefficient of variation of $3.8 \%$. Moreover, the $R$ of plasma samples from a dog infused with $\left[2-{ }^{14} \mathrm{C}\right]$ acetate analyzed in seven separate aliquots had a coefficient of variation of $4.8 \%$.

Plasma $\left[{ }^{14} \mathrm{C}\right]$ glucose $\mathrm{sp}$ act was calculated as two times lactate $\mathrm{sp}$ act. Plasma $\left[{ }^{3} \mathrm{H}\right]$ glucose sp act was determined after isolation of glucose by ion exchange chromatography as previously described (13).

\section{Plasma ${ }^{14} \mathrm{C} 3-\mathrm{OH}$-butyrate sp act}

$4 \mathrm{ml}$ of plasma was deproteinized by $7 \%$ perchloric acid, neutralized to pH 7 with $4 \mathrm{~N} \mathrm{KOH}$, and poured on a 9-ml bed volume AG1-XB formate form ion exchange resin column (Bio-Rad Laboratories). After a 40-ml water washing, the column was eluted with $2 \times 20 \mathrm{ml} 2 \mathrm{~N}$ acetic acid. The resultant eluates were dried (Speed Vac rotor concentrator, Savant Instruments, Inc.) and resuspended in $1 \mathrm{ml} 0.01 \mathrm{~N}$ $\mathrm{NaOH}$, combined, and dried again. Samples were resuspended and then heated at $50^{\circ} \mathrm{C}$ for $10 \mathrm{~min}$ to completely eliminate the small fraction of acetoacetate that might be present after the drying procedure. To the samples was added $0.02 \mathrm{ml}$ of $50 \%$ suspension of AG50$\mathrm{WB}$ resin in $\mathrm{H} 2 \mathrm{O}$ and the mixture was spun in a microfuge (Beckman Instruments Inc.). $0.19 \mathrm{ml}$ of the supernatant was then injected onto a $250 \times 4.6-\mathrm{mm} \mathrm{C} 18$ 10- $\mu \mathrm{m}$ column (Alltech Assoc., Inc., Deerfield, IL) protected by a $5 \times 6.5-\mathrm{mm} \mathrm{C18}$ guard cartridge (Waters Assoc.) and was eluted with $0.1 \mathrm{~N} \mathrm{NaHPO} 4$ (pH 2.5) buffer containing $1.5 \%$ methanol at $1.75 \mathrm{ml} / \mathrm{min}$ using UV $(214 \mathrm{~nm})$ detection. Under these conditions, 3-OH-Butyrate elutes at $4.5 \mathrm{~min}$ and is well separated from lactate and acetate, which elute at 2.5 and $2.7 \mathrm{~min}$, respectively. Since the amount of 3-OH-butyrate injected was below our detection limit, standards of lactate, acetate, and 3-OH-butyrate were injected before and after each sample to ensure reproducibility in the retention times. The 3-OH-butyrate fraction was collected in a volume of $1.75 \mathrm{ml}$, of which $0.05 \mathrm{ml}$ was used for micro-fluorometric determination of 3-OH-butyrate concentration (16). In separate experiments, recovery of external standards of 3-OH-butyrate ranged between 45 and $50 \%$; in studies of 14-h fasted subjects, 3-OH-butyrate concentrations in HPLC eluated ranged between 100 and $200 \mu \mathrm{mol} / \mathrm{liter}$, which were well above the sensitivity of the microfluorometric assay $(20 \mu \mathrm{mol} / \mathrm{liter})$. The remaining $1.7 \mathrm{ml}$ was used for determination of ${ }^{14} \mathrm{C}$-radioactivity.

Calculations. The term Y (molar ratio of flux of pyruvate into the Krebs cycle to the influx of acetyl CoA into the Krebs cycle) was calculated according to Strisower (1) from the equation: $Y=(R-2) / 2$, where $R$ is the ratio of the sp act of carbons $1,2,5$, and 6 to that of carbons 3 and 4 in glucose expressed as disintegrations per microgram carbon. This approach to calculate $\mathbf{R}$ was used rather than determination of the relative sp act of carbons 1 and 3 to compensate for possible incomplete randomization between fumarate and malate (17).

The theoretical sp act of intracellular phosphoenolpyruvate carbon relative to the sp act of intramitochondrial acetyl CoA carbon $(\mathrm{P})$ was calculated as proposed by Katz (8): $P=[2 / 3(5+4 Y)] /[2(1+Y)(1$ $+2 Y)]$. Plasma $\left[{ }^{14} \mathrm{C}\right] 3-\mathrm{OH}$-butyrate sp act was used as an approximation of intramitochondrial acetyl CoA sp act, and the intracellular phosphoenolpyruvate sp act was calculated as: (plasma $\left[{ }^{14} \mathrm{C}\right] 3-\mathrm{OH}-b u-$ tyrate sp act) $\times P$.

If all of plasma glucose were formed via the phosphoenolpyruvate gluconeogenic pathway, the sp act of plasma glucose would equal that of phosphoenolpyruvate. Therefore, percentage of overall glucose output due to phosphoenolpyruvate gluconeogenesis was calculated from the ratio of the sp act of plasma glucose and intracellular phosphoenolpyruvate: (plasma $\left[{ }^{14} \mathrm{C}\right]$ glucose $\mathrm{sp}$ act) $\div$ (plasma $\left[{ }^{14} \mathrm{C}\right] 3-\mathrm{OH}-\mathrm{bu}$ tyrate sp act) $\times P$.

The rate of overall glucose output $(\mathrm{RaG})$ was calculated by the steady state equation (18): $\mathrm{RaG}=\left[6-{ }^{3} \mathrm{H}\right]$ glucose infusion rate $(\mathrm{dpm} /$ $\mathrm{min} / \mathrm{kg}) \div$ plasma $\left[6{ }^{3} \mathrm{H}\right]$ glucose sp act $(\mathrm{dpm} / \mu \mathrm{mol})$. The rate of gluconeogenesis from the phosphoenolpyruvate pathway (micromoles per kilogram per minute) was calculated as the product of percent of overall glucose output from phosphoenolpyruvate and the rate of overall glucose output. The rate of glycogenolysis was calculated as the difference between the rate of overall glucose output and the rate of phosphoenolpyruvate gluconeogenesis, assuming that the latter approximated all of gluconeogenesis (see below).

The radiation exposure to subjects from the $\left[{ }^{14} \mathrm{C}\right]$ acetate was calculated using the Medical Internal Radiation Dosimetry System. Our preliminary experiments in dogs and human volunteers indicated that $\left[{ }^{14} \mathrm{C}\right]$ acetate would have to be infused at a rate of $1 \mu \mathrm{Ci} / \mathrm{min}$ to obtain a minimum of four to six times background disintegrations per minute in glucose carbons $1,2,5$, and 6 , and in plasma 3-OH-butyrate, because: $(i)$ it is not possible to degrade $>30 \mu \mathrm{mol}$ of glucose with the technique we used due to product inhibition of the initial enzymatic reaction; (ii) recovery of acetate, resulting from chemical degradation of lactate is only $30-40 \%$; and, iii) the plasma 3-OH-butyrate concentration is low $(0.10-0.2 \mathrm{mmol} / \mathrm{liter})$ and analytical recovery is only $50 \%$.

Subjects were infused at a rate of $1 \mu \mathrm{Ci} / \mathrm{min}$ for $260 \mathrm{~min}$ for each of the two experiments because preliminary studies indicated that 240 min of infusion was necessary to insure isotopic steady state. Thus, each subject received a total of $520 \mu \mathrm{Ci}$ of $\left[{ }^{14} \mathrm{C}\right]$ acetate.

The radiation exposure calculated by the Mayo Clinic radiation safety officer was 74 milliroentgen (mrem) and was based on the following assumptions:

(a) Acetate is metabolized similar to glucose. (b) Using the Medical Internal Radiation Dosimetry System, values for S (cummulated activity) are:

$$
\begin{aligned}
& S \text { liver }- \text { liver }=5.8 \times 10^{-5} \mathrm{rad} / \mu \mathrm{Ci} \cdot \mathrm{h} ; \\
& S \text { liver }- \text { whole body }=1.5 \times 10^{-6} \mathrm{rad} / \mu \mathrm{Ci} \cdot \mathrm{h} ; \\
& S \text { whole body }- \text { liver }=1.5 \times 10^{-6} \mathrm{rad} / \mu \mathrm{Ci} \cdot \mathrm{h} \text {; and } \\
& S \text { whole body }- \text { whole body }=1.5 \times 10^{-6} \mathrm{rad} / \mu \mathrm{Ci} \cdot \mathrm{h} .
\end{aligned}
$$

(c) Uptake of ${ }^{14} \mathrm{C}$ by liver is $25 \%$ of the administered dose (19). (d) Average half-life of glucose in body equals $67 \mathrm{~h}$ (based on glucose turnover rate of $1.8 \mathrm{mg} / \mathrm{kg}$ per $\min$ [20]).

Since the decay constant for ${ }^{14} \mathrm{C}$ is 0.693 , the radiation exposure per microcurie infused of $\left[{ }^{14} \mathrm{C}\right]$ acetate for liver and whole body was calculated as follows:

(a) Liver exposure (mrem $/ \mu \mathrm{Ci})$

$$
\begin{aligned}
& =\left[(1 / 0.693)(1 \mu \mathrm{Ci})(67 \mathrm{~h})(25 \%)\left(5.8 \times 20^{-5} \mathrm{rad} / \mu \mathrm{Ci} \cdot \mathrm{h}\right)\right] \\
& +\left[(1 / 0.693)(1 \mu \mathrm{Ci})(67 \mathrm{~h})(75 \%)\left(1.5 \times 10^{-6}\right)\right] \\
& =1.4 \times 10^{-3}+1.1 \times 10^{-4} \\
& =1.5 .
\end{aligned}
$$

(b) Whole body exposure (mrem $/ \mu \mathrm{Ci})$

$=\left[(1 / 0.693)(1 \mu \mathrm{Ci})(67 \mathrm{~h})(75 \%)\left(1.5 \times 10^{-6}\right)\right]$

$+\left[(1 / 0.693)(1 \mu \mathrm{Ci})(67 \mathrm{~h})(25 \%)\left(1.5 \times 10^{-6}\right)\right]$

$=1.1 \times 10^{-4}+3.6 \times 10^{-5}$

$=0.15$.

The radiation exposure to our subjects was also calculated by the radiation safety officer at the University of Pittsburgh. Using the data of Hellman et al. (21) indicating that the half-life of $\left[{ }^{14} \mathrm{C}\right]$ acetate is $81 \mathrm{~h}$, the calculated radiation exposure to our subjects was $104 \mathrm{mrem}$. This is $<10 \%$ of the allowable quarterly dose limit for a radiation worker (22). Since it has been calculated (23) that a single exposure of 1,000 mrem, a tenfold greater exposure than that calculated for the present study, would result in one excess death from cancer per 10,000 people, whereas the expected deaths from cancer for 10,000 people would be 1,600 (23), we considered these experiments to have an acceptable risk/benefit ratio. 
Unless stated otherwise, data are given as means \pm SEM and were analyzed using paired $t$ tests. A $P$ value $<0.05$ was considered significant.

\section{Results}

${ }^{14} \mathrm{C}-s p$ act of glucose carbons, ratio of sp act of external and internal carbons, ratio of flux of pyruvate and acetyl $\mathrm{Co} A$ into the Krebs cycle, and calculated sp act of phosphoenolpyruvate carbon relative to acetyl $\mathrm{COA}$ carbon (Table II). In overnight fasted subjects infused with $\left[2-{ }^{14} \mathrm{C}\right]$ acetate, the ratio of the ${ }^{14} \mathrm{C}$-sp act of the four external $(\mathrm{C} 1, \mathrm{C} 2, \mathrm{C} 5$, and $\mathrm{C} 6)$ and two internal (C3 and $\mathrm{C4}$ ) glucose carbons was $3.07 \pm 0.07$. This ratio $(R)$ decreased significantly when subjects were studied after the 66 -h fast $(2.69 \pm 0.03, P<0.05)$.

Since $Y=(R-2) / 2$, the calculated value for $Y$, the ratio of the fluxes of pyruvate and acetyl CoA into the Krebs cycle, was $0.54 \pm 0.03$ after the overnight fast; this decreased significantly after the 66 -h fast $(0.35 \pm 0.02, P<0.05)$. Thus, the influx of acetyl $\mathrm{CoA}$ in the Krebs cycle was approximately double the influx of pyruvate in the postabsorptive state and approximately triple the influx of pyruvate after the 66-h fast.

Based on these relative fluxes of carbons into the Krebs cycle via oxidative and gluconeogenic pathways, the calculated theoretical sp act of intracellular phosphoenolpyruvate carbon relative to that of intramitochondrial acetyl CoA carbon was $0.76 \pm 0.03$ after the overnight fast. This increased significantly to $0.94 \pm 0.02, P<0.02$ after the 66 -h fast.

Measured plasma glucose and 3-OH-butyrate ${ }^{14} \mathrm{C}$-sp activity, calculated intracellular phosphoenolpyruvate sp act, and percent of overall glucose output derived from phosphoenolpyruvate gluconeogenic pathway (Table III). The ${ }^{14} \mathrm{C}-\mathrm{sp}$ act of plasma glucose and 3-OH-butyrate are given in Table III. The specific activity of intracellular phosphoenolpyruvate calculated as plasma $3-\mathrm{OH}$-butyrate sp act times $P$ was $11.7 \pm 1.1$ $\mathrm{dpm} / \mu \mathrm{g}$ carbon after the overnight fast and $7.0 \pm 0.5 \mathrm{dpm} / \mu \mathrm{g}$ carbon after the 66-h fast. The percentage of overall glucose output derived from the phosphoenolpyruvate gluconeogenic pathway calculated as (plasma glucose ${ }^{14} \mathrm{C}-\mathrm{sp}$ act)/(plasma 3-OH-butyrate ${ }^{14} \mathrm{C}-\mathrm{sp}$ act) $\times \mathrm{P}$ was $28.4 \pm 1.6$ after the overnight fast; this increased significantly to $97.5 \pm 2.1 \%$ after the 66-h fast, $P<0.001$.

Plasma glucose concentrations and rates of overall glucose output, gluconeogenesis, and glycogenolysis (Table IV). After the overnight fast, plasma glucose concentration was $5.1 \pm 0.1$ $\mathrm{mmol} / \mathrm{liter}$; rates of overall glucose output, gluconeogenesis, and glycogenolysis were $12.52 \pm 0.50,3.57 \pm 0.28$, and $8.96 \pm 0.40 \mu \mathrm{mol} / \mathrm{kg}$ per min, respectively. After the $66-\mathrm{h}$ fast, plasma glucose concentration decreased to $3.1 \pm 0.1 \mathrm{mmol} /$ liter, $P<0.001$; rates of overall glucose output and glycogenolysis decreased to $7.56 \pm 0.61$, and $0.34 \pm 0.08 \mu \mathrm{mol} / \mathrm{kg}$ per min, respectively (both $P<0.001$ ). The rate of phosphoenolpyruvate gluconeogenesis increased more than twofold to $7.39 \pm 0.67 \mu \mathrm{mol} / \mathrm{kg}$ per $\min (P<0.001)$.

\section{Discussion}

In the present study, we applied the equations of a mitochondrial model of gluconeogenesis $(1,6-8)$ and used plasma 3-OH-butyrate sp act to approximate intramitochondrial pre-

Table II. ${ }^{14} \mathrm{C}$-sp act of Glucose Carbons, Ratio of sp act of External and Internal Glucose. Carbons, Relative Flux of Pyruvate and Acetyl CoA into the Krebs Cycle, and Calculated sp act of Phosphoenolpyruvate Carbon Relative to Acetyl CoA Carbon after 14- and 66-h Fasts

\begin{tabular}{|c|c|c|c|c|c|c|c|c|c|c|}
\hline \multirow[b]{2}{*}{ Subject } & \multicolumn{2}{|c|}{$\begin{array}{l}\mathrm{C} 1+\mathrm{C} 2+\mathrm{C} 5+\mathrm{C}^{*} \\
\text { sp act }\end{array}$} & \multicolumn{2}{|c|}{$\mathrm{C} 3+\mathrm{C} 4^{*} \mathrm{sp}$ act } & \multicolumn{2}{|l|}{$R^{\ddagger}$} & \multicolumn{2}{|l|}{$Y^{\S}$} & \multicolumn{2}{|l|}{$P \|$} \\
\hline & $\begin{array}{l}14-h \\
\text { fast }\end{array}$ & $\begin{array}{l}\text { 66-h } \\
\text { fast }\end{array}$ & $\begin{array}{l}14-h \\
\text { fast }\end{array}$ & $\begin{array}{l}66-\mathrm{h} \\
\text { fast }\end{array}$ & $\begin{array}{l}14-h \\
\text { fast }\end{array}$ & $\begin{array}{l}\text { 66-h } \\
\text { fast }\end{array}$ & $\begin{array}{l}\text { 14-h } \\
\text { fast }\end{array}$ & $\begin{array}{l}\text { 66-h } \\
\text { fast }\end{array}$ & $\begin{array}{l}14-h \\
\text { fast }\end{array}$ & $\begin{array}{l}\text { 66-h } \\
\text { fast }\end{array}$ \\
\hline 1 & 6.29 & & 1.83 & & 3.44 & & 0.72 & & 0.63 & \\
\hline 2 & 3.17 & & 1.13 & & 2.81 & & 0.40 & & 0.87 & \\
\hline 3 & 4.29 & & 1.29 & & 3.33 & & 0.66 & & 0.66 & \\
\hline 4 & 3.12 & & 0.96 & & 3.25 & & 0.63 & & 0.68 & \\
\hline 5 & 6.40 & 11.04 & 2.21 & 4.00 & 2.90 & 2.76 & 0.45 & 0.38 & 0.81 & 0.90 \\
\hline 6 & 2.96 & 10.12 & 1.04 & 3.58 & 2.85 & 2.83 & 0.42 & 0.41 & 0.85 & 0.86 \\
\hline 7 & 2.87 & 10.80 & 0.83 & 4.17 & 3.46 & 2.59 & 0.73 & 0.30 & 0.62 & 1.00 \\
\hline 8 & 1.27 & 8.00 & 0.44 & 3.09 & 2.89 & 2.59 & 0.45 & 0.30 & 0.82 & 0.99 \\
\hline 9 & 5.81 & 10.10 & 1.87 & 3.58 & 3.11 & 2.82 & 0.55 & 0.42 & 0.74 & 0.86 \\
\hline 10 & 5.42 & 6.70 & 1.62 & 2.54 & 3.35 & 2.64 & 0.67 & 0.32 & 0.65 & 0.96 \\
\hline 11 & 3.08 & 6.75 & 1.08 & 2.67 & 2.85 & 2.53 & 0.43 & 0.27 & 0.84 & 1.04 \\
\hline 12 & 5.48 & 8.08 & 1.88 & 3.08 & 2.91 & 2.62 & 0.46 & 0.31 & 0.81 & 0.98 \\
\hline 13 & 4.70 & 7.4 & 1.75 & 2.83 & 2.69 & 2.62 & 0.35 & 0.31 & 0.94 & 0.98 \\
\hline 14 & 2.96 & 7.13 & 0.92 & 2.46 & 3.22 & 2.90 & 0.61 & 0.45 & 0.69 & 0.82 \\
\hline Mean & 4.13 & 8.61 & 1.35 & 3.20 & 3.07 & 2.69 & 0.54 & 0.35 & 0.76 & 0.94 \\
\hline \pm SEM & 0.42 & 0.54 & 0.14 & 0.19 & 0.07 & 0.04 & 0.03 & 0.02 & 0.03 & 0.02 \\
\hline$P$ & & & & & & 0.0036 & & 0.0035 & & 0.0018 \\
\hline
\end{tabular}

* Disintegrations per minute per microgram carbon. ${ }^{\ddagger} R=(\mathrm{C} 1+\mathrm{C} 2+\mathrm{C} 5+\mathrm{C} 6 \mathrm{sp} \mathrm{act}) /(\mathrm{C} 3+\mathrm{C} 4 \mathrm{sp}$ act $) .{ }^{\S} Y=($ flux of pyruvate into $\mathrm{Krebs}$ cycle)/(flux of acetyl CoA into Krebs cycle). " $P=$ (phosphoenolpyruvate sp act)/(acetyl CoA sp act). 
Table III. Measured Plasma Glucose and 3-OH-Butyrate ${ }^{14} \mathrm{C}-\mathrm{sp}$ act, Calculated Intracellular Phosphoenolpyruvate ${ }^{14} \mathrm{C}-\mathrm{sp}$ act, and Percent of Glucose Output from Phosphoenolpyruvate Pathway after 14- and 66-h Fasts

\begin{tabular}{|c|c|c|c|c|c|c|c|c|}
\hline \multirow[b]{2}{*}{ Subject } & \multicolumn{2}{|c|}{$\begin{array}{l}\text { Glucose* } \\
{ }^{14} \mathrm{C}-\text { sp act }\end{array}$} & \multicolumn{2}{|c|}{$\begin{array}{l}\text { 3-OH-Butyrate* } \\
{ }^{14} \mathrm{C} \text {-sp act }\end{array}$} & \multicolumn{2}{|c|}{$\begin{array}{l}\text { Phosphenolpyruvate* } \\
{ }^{14} \mathrm{C} \text {-sp act }\end{array}$} & \multicolumn{2}{|c|}{$\begin{array}{l}\text { Percent glucose output from } \\
\text { phosphoenolypyruvate }\end{array}$} \\
\hline & $\begin{array}{l}\text { 14-h } \\
\text { fast }\end{array}$ & $\begin{array}{l}\text { 66-h } \\
\text { fast }\end{array}$ & $\begin{array}{l}\text { 14-h } \\
\text { fast }\end{array}$ & $\begin{array}{l}\text { 66-h } \\
\text { fast }\end{array}$ & $\begin{array}{l}14-h \\
\text { fast }\end{array}$ & $\begin{array}{l}\text { 66-h } \\
\text { fast }\end{array}$ & $\begin{array}{l}14-h \\
\text { fast }\end{array}$ & $\begin{array}{l}\text { 66-h } \\
\text { fast }\end{array}$ \\
\hline 1 & 4.80 & & 22.60 & & 14.24 & & 33.71 & \\
\hline 2 & 2.55 & & 13.90 & & 12.09 & & 21.09 & \\
\hline 3 & 3.28 & & 18.33 & & 12.10 & & 27.11 & \\
\hline 4 & 2.39 & & 16.80 & & 11.42 & & 20.92 & \\
\hline 5 & 5.01 & 8.56 & 24.00 & 9.77 & 19.44 & 8.79 & 25.77 & 97.35 \\
\hline 6 & 2.32 & 7.94 & 11.90 & 8.56 & 10.12 & 7.36 & 22.94 & 107.86 \\
\hline 7 & 2.19 & 8.58 & 14.60 & 9.40 & 9.05 & 9.40 & 24.19 & 91.28 \\
\hline 8 & 1.00 & 6.36 & 5.00 & 6.31 & 4.10 & 6.25 & 24.39 & 101.81 \\
\hline 9 & 4.60 & 7.96 & 21.00 & 10.12 & 15.54 & 8.70 & 29.60 & 91.46 \\
\hline 10 & 4.15 & 5.31 & 24.60 & 5.96 & 15.99 & 5.72 & 25.95 & 92.81 \\
\hline 11 & 2.90 & 5.39 & 8.29 & 5.42 & 6.96 & 5.64 & 41.65 & 95.62 \\
\hline 12 & 5.13 & 6.42 & 16.81 & 5.96 & 13.62 & 5.85 & 27.68 & 109.92 \\
\hline 13 & 3.72 & 5.89 & 12.30 & 6.44 & 11.56 & 6.31 & 32.17 & 93.33 \\
\hline 14 & 2.28 & 5.56 & 10.80 & 7.27 & 7.45 & 5.96 & 30.60 & 93.27 \\
\hline Mean & 3.31 & 6.79 & 15.78 & 7.52 & 11.69 & 6.99 & 28.41 & 97.47 \\
\hline \pm SEM & 0.34 & 0.42 & 1.58 & 0.56 & 1.08 & 0.46 & 1.65 & 2.15 \\
\hline$P$ & & & & & & & & 0.001 \\
\hline
\end{tabular}

* Disintegrations per minute per microgram carbon.

cursor sp act during infusion of $\left[2-{ }^{14} \mathrm{C}\right]$ acetate to estimate the magnitude of carbon exchange in the Krebs cycle and to assess the relative contributions of gluconeogenesis and glycogenolysis to overall glucose output in overnight and $2 \frac{1}{2}-\mathrm{d}(66 \mathrm{~h})$ fasted normal volunteers.
With this approach, we found that the ratio of the fluxes of pyruvate and acetyl CoA into the Krebs cycle was 0.54 after an overnight fast, a value comparable with that found in dogs (0.44) by Hetenyi (5) using the same approach; after the $2 \frac{1 / 2-d}{}$ fast, this ratio decreased to 0.35 in our subjects. Thus, the

Table IV. Plasma Glucose Concentrations and Rates of Overall Glucose Output, Gluconeogenesis, and Glycogenolysis after 14- and 66-h Fasts

\begin{tabular}{|c|c|c|c|c|c|c|c|c|}
\hline \multirow[b]{2}{*}{ Subject } & \multicolumn{2}{|c|}{ Plasma glucose } & \multicolumn{2}{|c|}{ Overall glucose output } & \multicolumn{2}{|c|}{ Gluconeogenesis } & \multicolumn{2}{|c|}{ Glycogenolysis } \\
\hline & $\begin{array}{l}\text { 14-h } \\
\text { fast }\end{array}$ & $\begin{array}{l}\text { 66-h } \\
\text { fast }\end{array}$ & $\begin{array}{l}\text { 14-h } \\
\text { fast }\end{array}$ & $\begin{array}{l}\text { 66-h } \\
\text { fast }\end{array}$ & $\begin{array}{l}\text { 14-h } \\
\text { fast }\end{array}$ & $\begin{array}{l}\text { 66-h } \\
\text { fast }\end{array}$ & $\begin{array}{l}\text { 14-h } \\
\text { fast }\end{array}$ & $\begin{array}{l}66-h \\
\text { fast }\end{array}$ \\
\hline & \multicolumn{2}{|c|}{$\mathrm{mmol} / \mathrm{liter}$} & \multicolumn{2}{|c|}{$\mu \mathrm{mol} / \mathrm{kg} / \mathrm{min}$} & \multicolumn{2}{|c|}{$\mu \mathrm{mol} / \mathrm{kg} / \mathrm{min}$} & \multicolumn{2}{|c|}{$\mu \mathrm{mol} / \mathrm{kg} / \mathrm{min}$} \\
\hline 1 & \multicolumn{2}{|l|}{5.28} & \multicolumn{2}{|l|}{13.20} & \multicolumn{2}{|l|}{4.45} & \multicolumn{2}{|l|}{8.75} \\
\hline 2 & \multicolumn{2}{|l|}{4.61} & \multicolumn{2}{|l|}{12.50} & \multicolumn{2}{|l|}{2.64} & \multicolumn{2}{|l|}{9.86} \\
\hline 3 & \multicolumn{2}{|l|}{5.28} & \multicolumn{2}{|l|}{15.50} & \multicolumn{2}{|l|}{4.20} & \multicolumn{2}{|l|}{11.30} \\
\hline 4 & \multicolumn{2}{|l|}{5.22} & \multicolumn{2}{|l|}{14.90} & \multicolumn{2}{|l|}{3.12} & \multicolumn{2}{|l|}{11.78} \\
\hline 5 & 4.78 & 2.50 & 11.90 & 5.23 & 3.07 & 5.09 & 8.83 & 0.14 \\
\hline 6 & 5.33 & 3.11 & 11.80 & 6.80 & 2.71 & 7.33 & 9.09 & 0.00 \\
\hline 7 & 5.17 & 2.78 & 11.26 & 7.02 & 2.72 & 6.41 & 8.54 & 0.61 \\
\hline 8 & 5.11 & 3.33 & 10.00 & 5.40 & 2.44 & 5.50 & 7.56 & 0.00 \\
\hline 9 & 4.89 & 3.28 & 9.75 & 6.12 & 2.89 & 5.60 & 6.86 & 0.52 \\
\hline 10 & 5.17 & 3.44 & 14.30 & 7.72 & 3.71 & 7.16 & 10.59 & 0.56 \\
\hline 11 & 5.22 & 3.33 & 15.30 & 10.70 & 6.37 & 10.23 & 8.93 & 0.47 \\
\hline 12 & 4.89 & 3.11 & 11.13 & 10.60 & 4.19 & 11.65 & 6.94 & 0.00 \\
\hline 13 & 5.00 & 3.33 & 11.40 & 8.80 & 3.67 & 8.21 & 7.73 & 0.59 \\
\hline 14 & 5.56 & 3.33 & 12.40 & 7.20 & 3.79 & 6.72 & 8.61 & 0.48 \\
\hline Mean & 5.11 & 3.15 & 12.52 & 7.56 & 3.57 & 7.39 & 8.96 & 0.34 \\
\hline$\pm \mathrm{SEM}$ & 0.07 & 0.09 & 0.50 & 0.61 & 0.28 & 0.67 & 0.40 & 0.08 \\
\hline$P$ & & 0.001 & & 0.001 & & 0.001 & & .001 \\
\hline
\end{tabular}


influx of carbons from acetyl $\mathrm{CoA}$ into oxaloacetate was about double the influx of carbons from pyruvate after an overnight fast and increased to triple the influx of carbons from pyruvate after the $2 \frac{1}{2}-\mathrm{d}$ fast.

From these values, one can, using the equations of Katz (8), calculate the degree to which the conventional isotopic approach would underestimate gluconeogenesis due to Krebs cycle carbon exchange: with uniformly labeled lactate or alanine, gluconeogenesis would be underestimated by $54 \%$ in the postabsorptive state and by $63 \%$ after a $2 \frac{1}{1 / 2}-\mathrm{d}$ fast; with these precursors labeled in the 3,2 , or 1 position, gluconeogenesis would be underestimated by 40,40 , and $82 \%$, respectively, in the postabsorptive state and by 51,51 , and $87 \%$, respectively, after a $2 \frac{1}{2}$-d fast.

With the present approach, which avoided this underestimation, we found that gluconeogenesis from the phosphoenolpyruvate pathway was responsible for $28 \%$ of overall glucose output in the postabsorptive state. The only major substrate that theoretically can be converted to glucose without transversing the phosphoenolpyruvate pathway is glycerol. Since $<3 \%$ of plasma glucose is derived from glycerol in the postabsorptive state $(9,10)$ and since some of glycerol probably traverses the phosphoenolpyruvate pathway on its way to glucose (11), gluconeogenesis via the phosphoenolpyruvate pathway could be considered to approximate nearly all of gluconeogenesis. Our finding that gluconeogenesis via the phosphoenolpyruvate pathway accounted for almost $100 \%$ of overall glucose output after a $21 / 2-d$ fast is consistent with this conclusion.

Previous attempts to quantitate the relative contributions of gluconeogenesis and glycogenolysis to overall glucose output in postabsorptive man have involved measurement of splanchnic substrate balance (24-26) or determination of the glycogen content of serial liver biopsies (12). Dietz et al. (24), Wahren et al. (25), and Nilsson et al. (26) measured the splanchnic balance of potential gluconeogenic substrates. Assuming that splanchnic balance represented hepatic balance, and that there was total conversion to glucose of substrates taken up by the splanchnic bed, their data indicated that gluconeogenesis accounted for $\sim 26 \%$ of overall hepatic glucose output. These estimates are similar to that found in the present study (28\%).

Nilsson and Hultman (12) found the rate of decrease in glycogen content of serial liver biopsies from overnight fasted normal volunteers to be $8.3 \mu \mathrm{mol}$ glucose $/ \mathrm{kg}$ per min. Assuming that the rate of overall hepatic glucose output of their subjects was similar to that found in the present and other studies $(27,28)$, i.e., $\sim 12 \mu \mathrm{mol} / \mathrm{kg}$ per min, and that all of the depleted glycogen entered plasma as glucose, this would indicate that glycogenolysis accounted for $\sim 70 \%$ of overall hepatic glucose output. In the present study, we calculated glycogenolysis in our overnight fasted subjects to be $8.9 \mu \mathrm{mol} / \mathrm{kg}$ per min and to account for $72 \%$ of overall glucose output.

Thus, the results of the present study agree quite well with those obtained by other more invasive techniques. Furthermore, Nilsson and Hultman (12) have found that there is near complete depletion of glycogen in liver biopsies obtained from 60-h fasted human subjects. After this duration of fasting, gluconeogenesis should, therefore, account for essentially all of glucose output. Our finding in the present study that gluconeogenesis accounted for $97 \pm 2 \%$ of glucose output in $66-\mathrm{h}$ fasted volunteers, thus provides additional support for the validity of the isotopic approach that we used.
Note, however, that the present approach rests upon certain simplifications and assumptions $(4,8,29)$. Strisower's model assumes that there is no further dilution of label in the Krebs cycle beyond citrate synthesis. This simplification will not hold if glutamine and other amino acids contribute appreciable carbons to gluconeogenesis (29). However, glutamine and amino acids other than alanine are rather minor gluconeogenic substrates (30) and, thus, disregarding these fluxes should not invalidate the model.

Strisower's model also assumes that hepatic pyruvate kinase activity is minimal. Although Hetenyi et al. (31) observed labeling of plasma lactate during infusion of $\left[2-{ }^{14} \mathrm{C}\right]$ acetate in dogs, compatible with there being substantial pyruvate kinase activity, it has been calculated (8) that even if pyruvate kinase activity were $50 \%$ of pyruvate carboxylase activity (which would be unlikely in the postabsorptive state), phosphoenolpyruvate sp act would be altered $<10 \%$; this would only minimally affect the results obtained with the model.

Another assumption is that reincorporation into glucose of ${ }^{14} \mathrm{CO}_{2}$ formed from the label acetate used as tracer is negligible. The large bicarbonate pool, and studies of Hetenyi et al. (31), indicate that this is a reasonable assumption. It is further assumed that negligible ${ }^{14} \mathrm{C}$ is incorporated into glucose from $\left[{ }^{14} \mathrm{C}\right.$ ]acetone derived from $\left[{ }^{14} \mathrm{C}\right]$ acetate, since this would result in a labeling of plasma glucose carbons such that the ratio of the specific activities of its internal and external carbons could no longer be used to calculate Krebs cycle carbon exchange. This seems to be a reasonable assumption, since it can be calculated from the data of Kreiberg et al. (13), Skutches et al. (32), and Reichard et al. (33) that $<4 \%$ of the infused acetate would be expected to be converted to acetone $(32,33)$, and that $<5 \%$ of this acetone could be converted to glucose $(13,33)$.

Application of the equations proposed by Katz using the relative sp act of glucose carbons 1 and 3 assumes that there is complete equilibration between malate and fumarate, so that the labeling pattern in oxaloacetate is symmetrical (8). However, there is evidence that equilibration between fumarate and malate may be incomplete (17). This could represent a problem with use of labeled precursors other than acetate (e.g., lactate, alanine, or pyruvate). Nevertheless, the approach in the present studies using the average sp act of carbons 1, 2, 5, and 6 , and of carbons 3 and 4, would compensate for any disequilibration and obviate this potential problem. Moreover, the simultaneous determination of the sp act of these carbons using HPLC analysis of glucose degradation products in the present studies improves precision of measurements in which a small experimental error can greatly affect the results (5).

In our approach to determining the contribution of gluconeogenesis from phosphoenolpyruvate to overall glucose output, we calculated intracellular phosphoenolpyruvate sp act from the plasma 3-OH-butyrate ${ }^{14} \mathrm{C}$-sp act. Ideally, one should use the intramitochondrial acetyl CoA sp act; obviously this was not possible in our human subjects. We therefore assumed that plasma 3-OH-butyrate sp act would closely approximate intramitochondrial acetyl CoA sp act.

The near symmetrical distribution of ${ }^{14} \mathrm{C}$ in the 3-OH-butyrate molecule by rat liver perfused with $\left[{ }^{14} \mathrm{C}\right]$ acetate $(34)$ indicates that acetyl CoA is essentially the sole precursor for ketone bodies in liver, where ketone bodies are produced almost exclusively (35). Conceivably, exchange between 3-OHbutyrate formed in liver and acetoacetyl CoA formed during fatty acid oxidation in peripheral tissue could result in an un- 
derestimation of the sp act of hepatic acetyl CoA, as reflected by plasma 3-OH-butyrate sp act (34); however, Nosadini et al. (36) have shown that in normal human volunteers such exchange is negligible.

Other than the present study in man, only Hetenyi and co-workers have used the Strisower model in an attempt to quantitate gluconeogenesis more precisely $(4,5)$. It is important to point out certain differences in their approach and the one used here. As in the present report, Hetenyi et al. $(4,5)$ infused $\left[2-{ }^{14} \mathrm{C}\right]$ acetate; however, they measured the sp act of carbons 1 and 3 in plasma glucose via separate chemical reactions, and not the average sp act of all the external and internal carbons, which was done simultaneously in the present study.

Moreover, although both approaches used the same equation to calculate $\mathrm{Y}$, the relative influx of carbon from pyruvate and $\mathrm{CO}_{2}$ and from acetyl $\mathrm{CoA}$ into the oxaloacetate pool, Hetenyi and colleagues $(4,5)$ calculated the sp act of oxaloacetate relative to that of acetyl CoA as $1 /(1+2 Y)$. As Katz has pointed out (8), the relative $\mathrm{sp}$ act of phosphoenolpyruvate should have been calculated, rather than that of oxaloacetate; moreover, the equation that was used applies for an infusion of [U- $\left.{ }^{14} \mathrm{C}\right]$ acetate, not $\left[2-{ }^{14} \mathrm{C}\right]$ acetate, in the Strisower model.

More importantly, the approach of Hetenyi and colleagues $(4,5)$ was aimed at developing a correction factor to compensate for Krebs cycle carbon exchange so that the incorporation into glucose of carbons from a specific gluconeogenic precursor, such as lactate, could be quantitated. Their approach would require either two separate experiments or simultaneous use of ${ }^{13} \mathrm{C}$ - and ${ }^{14} \mathrm{C}$-labeled precursors, whereas the present approach traces all carbon flux through the phosphoenolpyruvate gluconeogenic pathway with one labeled precursor in a single experiment. Finally, the present approach does not require assumptions to be made about pyruvate dehydrogenase activity, whereas with use of lactate as the labeled precursor, as suggested by Hetenyi et al. (5), pyruvate dehydrogenase activity would influence their correction factor.

In summary, the present study describes the use in man of an isotopic approach to quantitate the contribution of glycogenolysis and gluconeogenesis to overall glucose output based on estimation of Krebs cycle carbon exchange (6-8). Our results using this approach indicate that in postabsorptive man, influx of carbon into the Krebs cycle from acetyl CoA is approximately twice that from pyruvate and $\mathrm{CO}_{2}$, and this increases $50 \%$ after a $2 \frac{1}{2} 2$-d fast. This carbon exchange would result in a $40-90 \%$ underestimation of gluconeogenesis measured by the conventional isotopic approach, depending on the labeled precursor used. The approach used herein thus overcomes a major limitation of previous isotopic techniques. That the results obtained with this approach agree well with those obtained by splanchnic balance and serial liver biopsies techniques, and the finding in the present study that gluconeogenesis accounted for nearly all of glucose output after a $2 \frac{1}{2} 2$-d fast, support the validity of the model on which this approach is based.

\section{Acknowledgments}

We are grateful for the excellent help of L. Smith, the Clinical Research Center staff, and the superb editorial assistance of $P$. Voelker and $C$. Butler.

Dr. Consoli is the recipient of a scholarship from the Italian Ministry of Public Education. This work is funded in part by grants from the U. S. Public Health Service (AM-20411, AM-33919, AM-07352,
RR-00585, and RR-00056), the Italian Ministry of Public Education, and the Juvenile Diabetes Foundation.

\section{References}

1. Weinman, E., E. Strisower, and I. Chaikoff. 1952. Conversion of fatty acids to carbohydrate: application of isotope to this problem and role of Krebs cycle as a synthesis pathway. Physiol. Rev. 37:252-272.

2. Krebs, H., R. Hems, M. Weidemann, and R. Speake. 1966. The fate of isotopic carbon in kidney cortex synthesizing glucose from lactate. Biochem. J. 101:242-249.

3. Strisower, E., G. Kohler, and I. Chaikoff. 1952. Incorporation of acetate carbons into glucose by liver slices of normal and alloxan diabetic rats. J. Biol. Chem. 198:115-126.

4. Hetenyi, G., and C. Ferrarotto. 1983. Correction for metabolic exchange in the calculation of rate of gluconeogenesis. Biochem. Med. 29:372-378.

5. Hetenyi, G. 1979. Correction for the estimation of plasma glucose synthesis from the transfer of ${ }^{14} \mathrm{C}$ atoms from labeled sustrates in vivo: a preliminary report. Can. J. Physiol. Pharmacol. 57:767-763.

6. Katz, J., and N. Grunnet. 1979. Estimation of metabolic pathways in steady-state in vivo. Rates of tricarbotylic acid and pentose cycles. In Techniques in Metabolic Research. H. L. Kornberg, editor. Elsevier/North Holland, Amsterdam. 1-18.

7. Rognstad, R., and J. Katz. 1972. Gluconeogenesis in the kidney cortex. J. Biol. Chem. 247:6047-6054.

8. Katz, J. 1985. Determination of gluconeogenesis in vivo with ${ }^{14} \mathrm{C}$ labeled substrates. Am. J. Physiol. 248:R391-R399.

9. Bortz, W., P. Paul, A. Haff, and W. Holmes. 1972. Glycerol turnover and oxidation in man. J. Clin. Invest. 51:1537-1546.

10. Nurjhan, N., P. Campbell, F. Kennedy, J. Miles, and J. Gerich. 1986. Insulin dose response characteristics for suppression of glycerol release and conversion to glucose in man. Diabetes. 35(12):13261331.

11. Gauthier, C., M. Vranic, and G. Hetenyi. 1983. Nonhypoglycemic glucoregulation: role of glycerol and glucoregulatory hormones. Am. J. Physiol. 244:E373-E379.

12. Nilsson, L., and E. Hultman. 1973. Liver glycogen in man. The effect of total starvation or a carbohydrate-poor diet followed by carbohydrate refeeding. Scand. J. Clin. Lab. Invest. 32:325-330.

13. Kreisberg, R., A. Siegal, and W. Owen. 1972. Alanine and gluconeogenesis in man: effects of ethanol. J. Clin. Endocrinol. Metab. 34:876-883.

14. Rognstad, R., and J. Woronberg. 1968. An enzymatic-chemical degradation of glucose. Anal. Biochem. 25:448-451.

15. Katz, J., S. Abraham, and I. Chaikoff. 1955. Analytical procedures using a combined combustion-diffusion vessel. Anal. Biochem. 27:155-156.

16. Williamson, D., and J. Nellanby. 1974. D-(-)-3-hydroxybutyrate. In Methods of Enzymatic Analysis. Vol. 4. H. Bergmeyer, editor. Academic Press, Inc., New York. 1836-1837.

17. Grunnet, N., and J. Katz. 1978. Effect of ammonia and norvaline on lactate metabolism in hepatocytes from starved rats. Biochem. J. 172:595-603.

18. Steele, R. 1959. Influence of glucose loading and of injected insulin on hepatic glucose output. Ann. NY Acad. Sci. 82:420-430.

19. Katz, L., M. Glickman, S. Rapoport, E. Ferrannini, and R. DeFonzo. 1983. Splanchnic and peripheral disposal of oral glucose in man. Diabetes. 32:675-679.

20. Rizza, R., C. Verdonk, J. Miles, J. Service, and J. Gerich. 1979. Effect of intermittent endogenous hyperglucagonemia on glucose homeostasis in normal and diabetic man. J. Clin. Invest. 63:1119-1123.

21. Hellman, L., W. Peacock, M. Eideinoff, R. Rosenfeld, I. Gallagher, and K. Dobriner. 1953. The metabolic fate of radioactive carbon labelled glycine and acetate in humans. Radioisotope Techniques, medical and physiological applications. Her Majesty's Stationary Office. 1:299-320. 
22. Commission of the ICRP. 1977. Recommendations of the International Commission on Radiological Protection. Ann. ICRP (Int. Comm. Radiol. Prot.). 1:21.

23. Committee on the Biological Effects of Ionizing Radiations, editors. 1980. The effects on populations of exposure to low levels of ionizing radiation: 1980. National Academy Press, Washington, D.C. 45.

24. Dietze, G., M. Wicklmayr, U. Hepp, W. Bogner, H. Mehnert, H. Czempiel, and H. Henftling. 1976. On gluconeogenesis of human liver: accelerated hepatic glucose production by increased precursor supply. Diabetologia. 12:555-561.

25. Wahren, J., P. Felig, E. Cerasi, and R. Luft. 1972. Splanchnic and peripheral glucose and amino acid metabolism in diabetes mellitus. J. Clin. Invest. 51:1870-1878.

26. Nilsson, N., P. Furst, and E. Hultman. 1973. Carbohydrate metabolism of the liver in normal man under varying dietary conditions. Scand. J. Clin. Lab. Invest. 32:325-330.

27. Garber, A., P. Cryer, J. Santiago, M. Haymond, A. Pagliara, and D. Kipnis. 1976. The role of adrenergic mechanisms in the substrate and hormonal response to insulin-induced hypoglycemia in man. J. Clin. Invest. 58:7-15.

28. Rizza, R., L. Mandarino, and J.. Gerich. 1981. Dose-response characteristics for effects of insulin on production and utilization of glucose in man. Am. J. Physiol. 240:E630-E639.
29. Kelleher, J. 1986. Gluconeogenesis from labeled carbon: estimating isotope dilution. Am. J. Physiol. 250:E296-E305.

30. Ruderman, N. 1975. Muscle amino-acid metabolism and gluconeogenesis. Ann. Rev. Med. 26:245-258.

31. Hetenyi, G., B. Lussier, C. Ferrarotto, and J. Radziuk. 1982. Calculation of the rate of gluconeogenesis from the incorporation of $\mathrm{C} 14$ atoms from labeled bicarbonate or acetate. Can. J. Physiol. Pharmacol. 60:1603-1608.

32. Skutches, C. L., C. P. Holroyde, R. N. Myers, P. Paul, and G. A. Reichard. 1979. Plasma acetate turnover and oxidation. J. Clin. Invest. 64:708-712.

33. Reichard, G. A., A. C. Haff, C. L. Skutches, P. Paul, C. P. Holroyde, and O. E. Owen. 1979. Plasma acetone metabolism in the fasting human. J. Clin. Invest. 63:619-626.

34. Kosugi, K., R. Scofield, V. Chandramouli, K. Kumaran, W. Schumann, and B. Landau. 1986. Pathways of acetone's metabolism in the rat. J. Biol. Chem. 261:3952-3967.

35. Brady, P., R. Scofield, S. Ohgaku, W. Schumann, G. Bartsch, J. Margolis, K. Kumaran, A. Horvat, S. Mann, and B. Landau. 1982. Pathways of acetoacetate's formation in liver and kidney. J. Biol. Chem. 257:9290-9293.

36. Nosadini, R., A. Avogaro, L. Sacca, C. Vigorito, S. De Kreutzenberg, C. Cobelli, G. Toffolo, R. Trevisan, P. Tessari, A. Tiengo, and G. Crepaldi. 1985. Ketone body metabolism in normal and diabetic skeletal muscle. Am. J. Physiol. 249:E131-E136. 